\title{
APP GeoGebra Graphing Calc: articulaçōes da Matemática e tecnologias na Educação
}

\section{Básica}

\author{
Fernanda Teresa Moro*, Scheila Andretta Rossatto**
}

\section{Resumo}

O ensino da Matemática, em muitos contextos, ainda se encontra desvinculado das tecnologias. Os recursos, como as tecnologias digitais, de maneira geral, são pouco utilizados nos processos de ensino e de aprendizagem nas diferentes disciplinas, aspecto esse reforçado pela carência de formação tecnológica dos professores e pela cultura escolar predominante, na qual há ênfase à abordagem expositiva do conhecimento. O enfoque, na maioria das vezes, tem consistido na transmissão do conteúdo matemático escolar, uma vez que o ensino nas aulas de matemática ocorre frequentemente mediante a apresentação de conceitos, leis e fórmulas, de forma desarticulada, vazios de significado e distanciados das tecnologias digitais, constituindo-se em um entrave no aprendizado. O uso de tecnologias tem sido frequentemente apontado, em discussões acadêmicas, como relevante recurso didático. As tecnologias digitais podem assumir uma importância fundamental na promoção de aprendizagens significativas em matemática, pois ajudam os alunos a aprender através do estabelecimento de inter-relações entre os saberes teóricos e práticos inerentes aos processos do conhecimento escolar. Neste contexto, este trabalho apresenta um relato de experiência desenvolvido no $1^{\circ}$ ano do Ensino Médio em uma escola da rede privada do município de Erechim, RS. O objetivo do trabalho é desenvolver e investigar ações de intervenção para problematizar e aprimorar o ensino de Matemática, possibilitando a exploração de funções de $1^{\circ}$ e $2^{\circ}$ graus com recursos tecnológicos. Para este trabaIho foi utilizado o APP GeoGebra Graphing Calc, que permite o uso nos próprios Smartphones dos estudantes. Espera-se que este trabalho possa contribuir a outros professores para que os mesmos passem a incorporar as tecnologias em sua prática pedagógica.

Palavras-chave: Tecnologias Digitais. APP GeoGebra. Ensino Médio. Aprendizagem Significativa.

\footnotetext{
- Doutoranda em Ensino pela Universidade do Vale do Taquari (Univates). Mestre em Ensino de Ciências Exatas (Univates). Professora de Matemática e Física no Ensino Médio do Colégio Franciscano São José - Erechim/ RS. E-mail: nanda_moro@yahoo.com.br

** Mestranda em Educação pela Universidade Federal da Fronteira Sul (UFFS). Professora de Matemática no Ensino Fundamental e Médio do Colégio Franciscano São José - Erechim/RS. E-mail: scheilar@yahoo.com.br
}

Recebido em: 09/09/2019 - Aceito em: 18/11/2019.

https://doi.org/10.5335/rbecm.v2i2.9903 


\section{Introdução}

A prática pedagógica desenvolvida por muitos professores no processo de ensino da Matemática constitui-se especialmente na apresentação de conceitos, exemplos, exercícios de fixação e aplicações de fórmulas. $\mathrm{O}$ desinteresse e a desmotivação para as aulas de Matemática, tem proporcionado várias discussões, tanto no âmbito das escolas de educação básica, quanto em eventos científicos da área que aproximam as pesquisas realizadas nas Universidades com o trabalho dos professores da Educação Básica. No último Encontro Nacional de Educação Matemática (2019), vários debates salientaram a necessidade de metodologias inovadoras, principalmente na Educação Básica, que coloquem o estudante em uma posição mais ativa no processo de aprendizagem.

A integração de softwares dinâmicos para tratamento da Matemática, aplicativos e atividades investigativas podem tornar as aulas mais atrativas e interessantes, auxiliando na construção de conceitos em determinados conteúdos, possibilitando novos direcionamentos e implementações em sala de aula. Tornou-se comum o uso do termo "tecnologias digitais" (TD), sendo esta fase caracterizada por vários aspectos que provocam inquietações, questionamentos e dúvidas a serem ainda formuladas. Isso revela a quarta fase como um cenário exploratório e produtivo ao desenvolvimento de investigações e pesquisas. Autores como Borba (2002), Fiorentini e Lorenzatto (2006) e Souza (2012) destacam que o uso do software tem boa aceitação pela maioria dos estudantes, proporciona a interação, melhorando o desempenho dos estudantes. Araújo (2014) enfatiza em sua pesquisa que o GeoGebra possibilita condições para o reconhecimento da representação gráfica de uma função polinomial.

Baseado nestes pressupostos, foi realizada uma atividade com os estudantes do $1^{\circ}$ ano do Ensino Médio de uma escola rede privada do município de Erechim, com o aplicativo para celular do GeoGebra. O conteúdo abordado envolveu as interpretações e representações gráficas das funções de $1^{\circ}$ e $2^{\circ}$ graus. A proposta foi desenvolvida num total de 6 horas e envolveu a explicação teórica dos conteúdos em sala de aula e aplicação dos conceitos estudados no APP GeoGebra Graphing Calc. O objetivo do trabalho foi identificar e analisar as construções e representações matemáticas dos estudantes do $1^{\circ}$ ano do Ensino Médio no referido $A P P$.

A tentativa de avançar para uma formação menos reducionista torna-se significativa quando a área de Matemática é pensada sem características de fragmentação e linearidade, permitindo aos estudantes fazer explorações das mais variadas 
naturezas. Faz-se necessário repensar práticas que estejam na perspectiva da inserção de recursos tecnológicos, que permitam aos estudantes a análise de diversos parâmetros simultaneamente.

\section{Tecnologias digitais e o ensino da matemática}

A forma acelerada com que as inovações tecnológicas vêm se apresentando, representa uma característica notável em nossa sociedade e, também, no ambiente escolar. As dimensões da inovação tecnológica possibilitam a exploração de novas situações, bem como o aparecimento de meios alternativos para a educação e, em especial, para o ensino e a aprendizagem de Matemática. Nesse sentido, é relevante argumentar acerca da evolução no uso de tecnologias no ensino. Borba et al. (2018) apresenta uma perspectiva organizada em quatro fases sobre o histórico do uso de tecnologias na educação Matemática no Brasil.

A primeira fase relata a discussão de calculadoras simples e científicas e de computadores em educação Matemática, por volta de 1980. A característica principal desta fase foi o uso do software LOGO, que teve início em 1985. A segunda fase teve início na metade dos anos 1990, a partir da popularidade e acessibilidade do uso de computadores pessoais. Diversos softwares educacionais foram desenvolvidos por empresas. Os professores precisaram sair da zona de conforto e se desafiar a vivenciar o risco de lidar com as tecnologias em ambientes educacionais. $\mathrm{O}$ uso de softwares gráficos, calculadoras gráficas ou computadores usuais, fizeram com que novos tipos de problemas matemáticos pudessem ser explorados e elaborados em diferentes níveis de ensino.

A terceira fase, por volta de 1999, iniciou com o surgimento da internet como fonte de informação e como meio de comunicação entre professores e estudantes e, também para realização de cursos, formação continuada, chats e fóruns de discussões, por exemplo. Esta fase tem uma importante interação com a formação inicial e continuada de professores. A quarta fase, que é atual, surgiu em meados de 2004 com o desenvolvimento da internet rápida, com qualidade de conexão e aprimoramento ao acesso transformando a comunicação online.

Nesta perspectiva, de exploração de novas possibilidades de tecnologias digitais no ensino, é que se insere este trabalho, Neste sentido, o professor tem papel fundamental: mediador do processo de construção do conhecimento. Para possibilitar 
a aprendizagem, o professor precisa partir de uma provocação, um estímulo para a motivação, uma capacidade de indução, que permita ao estudante perceber que aquilo que irá aprender é realmente importante para ele. Para Vasconcellos (2005, p. 76):

O papel do educador, dessa forma, não seria apenas de ficar passando informações, mas de provocar no outro a abertura para a aprendizagem e de colocar meios que possibilitem e direcionem esta aprendizagem. A provocação para a aprendizagem tem a ver com a sensibilidade para com as pessoas a quem se dirige, com o significado que aquilo tem para ele, bem como a correlação que tem com a existência.

É relevante que o professor seja o mediador na construção do conhecimento, relacionando o contexto vivenciado pelo estudante na escola. Desta maneira, é possível estabelecer sentido ao conteúdo, bem como significado à aprendizagem. A construção do conhecimento consiste em oportunizar que o estudante faça o confronto com o objeto de forma a compreendê-lo, realizando relações de causa e efeito. Através do seu estudo, o estudante consegue conhecer o objeto e tirar conclusões sobre o mesmo, para construir novos conhecimentos. É nesse momento que o auxílio do professor para mobilizar e estimular a busca pelo conhecimento é imprescindível, mostrando uma reflexão sobre o conteúdo estudado. Cabe, então, aos profissionais da educação saber escolher o melhor recurso, ou aquele que mais se adapta ao seu objetivo em sala de aula.

Ao pensar os atos de ensinar e aprender, é indispensável criar as oportunidades concretas para experimentar a construção/produção do conhecimento. E, neste sentido, a maneira como os conteúdos são apresentados contribui para esta construção ser realizada. De acordo com Borba (2002, p. 135):

Eu gosto de pensar que a informática não melhora nem piora o ensino, ela transforma o ensino e transforma a aprendizagem e ela transforma a forma como as pessoas produzem conhecimento. A gente vê que a utilização da informática possibilita que argumentos visuais sejam utilizados com muito mais frequência, porque é uma característica da mídia informática.

Na pretensão de encontrar referencial que abordasse o descritor - aprendizagem significativa da matemática com uso de tecnologia - foi realizada uma revisão de literatura com base em trabalhos encontrados no Banco de Teses e Dissertações da Capes, no período de 2012 a 2017. Na busca realizada elencaram-se 15 trabalhos, destes, 4 foram utilizados para a escrita deste relato de experiência, por aproximarem-se da proposta apresentada. O quadro 1 apresenta os trabalhos selecionados, os autores, as instituições e o ano de publicação. 
Quadro 1: Demonstrativo das dissertações selecionadas

\begin{tabular}{|c|c|l|l|l|}
\hline No & Ano & \multicolumn{1}{|c|}{ Autores } & \multicolumn{1}{|c|}{ Título } & \multicolumn{1}{|c|}{ Instituição } \\
\hline 01 & 2012 & $\begin{array}{l}\text { Francisco Ademir } \\
\text { Lopes de Souza }\end{array}$ & $\begin{array}{l}\text { O uso do software GeoGebra como } \\
\text { ferramenta pedagógica no estudo de } \\
\text { funções quadráticas em turmas de 9 } \\
\text { ano do ensino fundamental }\end{array}$ & $\begin{array}{l}\text { Universidade Federal do } \\
\text { Ceará }\end{array}$ \\
\hline 02 & 2013 & $\begin{array}{l}\text { Alexandre de } \\
\text { Mattos Teixeira }\end{array}$ & $\begin{array}{l}\text { Aprendizagem Significativa de Fun- } \\
\text { ções através do GeoGebra e de tipos } \\
\text { digitais? }\end{array}$ & $\begin{array}{l}\text { Centro Federal de Edu- } \\
\text { cação Tecn. Celso Su- } \\
\text { ckow da Fonseca }\end{array}$ \\
\hline 03 & 2014 & $\begin{array}{l}\text { Wellington Alves } \\
\text { de Araujo }\end{array}$ & $\begin{array}{l}\text { O GeoGebra: uma experimentação na } \\
\text { abordagem da Função Afim }\end{array}$ & $\begin{array}{l}\text { Fundação Universidade } \\
\text { Federal de Sergipe }\end{array}$ \\
\hline 04 & 2016 & $\begin{array}{l}\text { Simone Krause } \\
\text { Sucker }\end{array}$ & $\begin{array}{l}\text { A motivação para aprender do nativo } \\
\text { digital pela perspectiva de professo- } \\
\text { res, alunos e da neurociência. }\end{array}$ & $\begin{array}{l}\text { Pontifícia Universidade } \\
\text { Católica do Rio Grande } \\
\text { do Sul }\end{array}$ \\
\hline
\end{tabular}

Fonte: As autoras, 2019.

O uso das tecnologias digitais na educação pode proporcionar processos de comunicação mais participativos, tornando a relação professor-aluno interativa e dialógica. Contudo, esperar que a tecnologia faça as mudanças acontecerem automaticamente, é um equívoco, isto é, ela pode ser apenas a extensão de um modelo tradicional. A tecnologia sozinha não garante a comunicação de duas vias, bem como não assegura a participação real dos envolvidos nos processos de ensino e de aprendizagem.

\section{A atividade proposta}

A proposta aqui apresentada foi desenvolvida com 52 estudantes do $1^{\circ}$ ano do Ensino Médio, em uma escola da rede privada, do município de Erechim, Rio Grande do Sul, com o conteúdo de funções de $1^{\circ}$ e $2^{\circ}$ graus, em especial a construção e análise gráfica destas funções. É importante mencionar que as atividades foram desenvolvidas nas duas turmas, tanto para evitar comparações entre as mesmas, quanto aos recursos que o professor utilizou nas aulas.

Os estudantes instalaram em seus smartphones o APP do GeoGebra (Graphing Calc). Inicialmente, se familiarizaram com o recurso e após, em duplas, receberam roteiros de atividades que deveriam ser realizadas no referido APP. A Figura 1 apresenta os estudantes ${ }^{1}$ de uma turma durante a atividade proposta. 
Figura 1: Estudantes durante a realização da atividade proposta

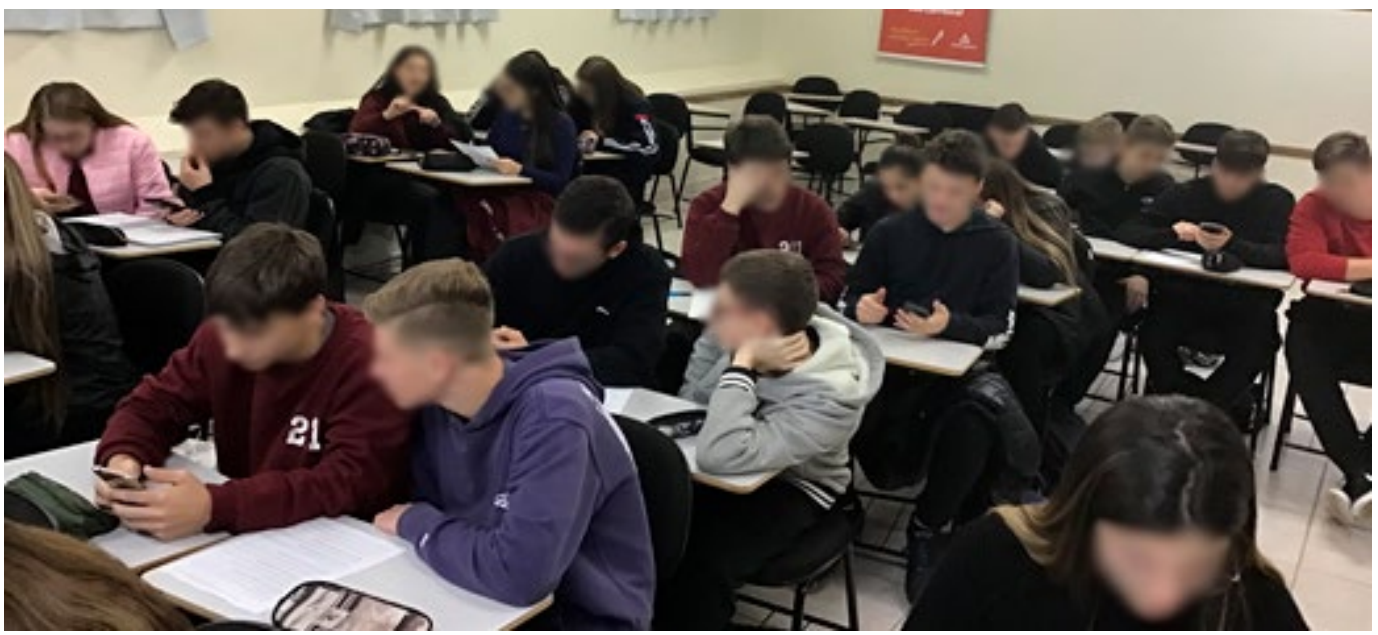

O objetivo do trabalho foi identificar e analisar as construções e representações matemáticas dos estudantes do $1^{\circ}$ ano do Ensino Médio no GeoGebra. Os estudantes precisaram construir funções de $1^{\circ}$ e $2^{\circ}$ graus, com diferentes coeficientes e responder questões relacionadas às mudanças dos parâmetros das funções, à declividade das retas, concavidade e vértice das parábolas. Também foi explorado o "controle deslizante" disponível no aplicativo. A Figura 2 apresenta os estudantes durante a realização das atividades propostas.

Figura 2: Estudantes realizando as atividades no APP GeoGebra
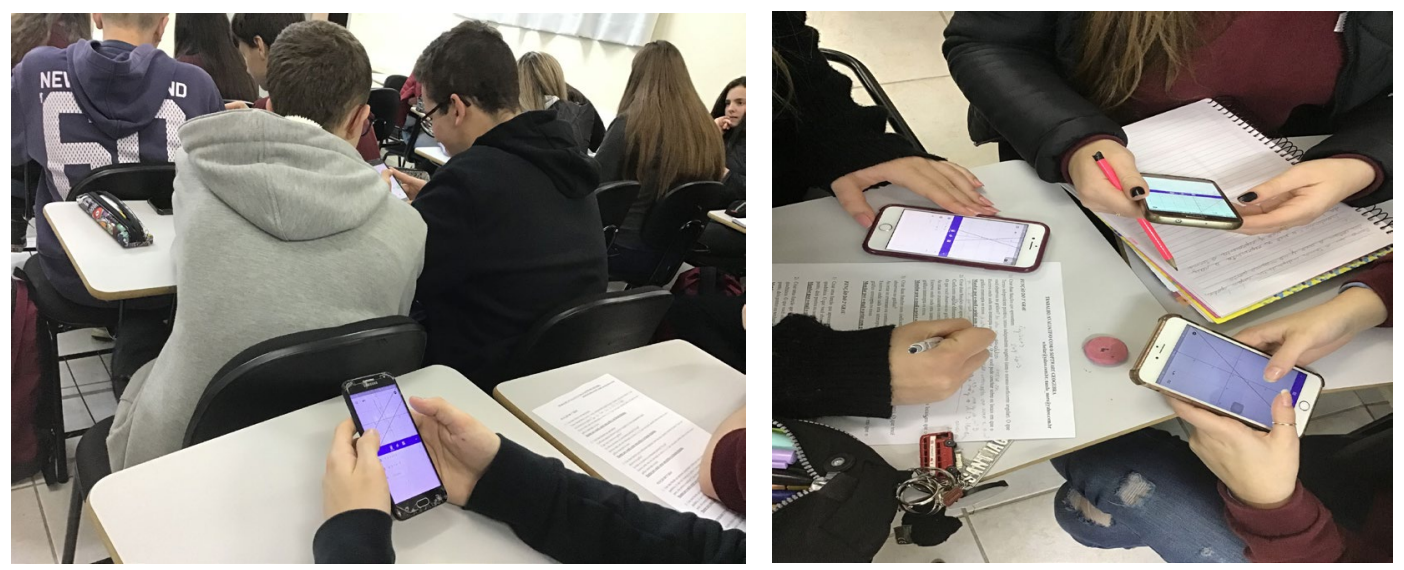
Cabe destacar que todas as respostas eram enviadas por e-mail com a imagem gerada pelo aplicativo, para a avaliação das professoras. A atividade que envolvia o controle deslizante foi enviada para os professores em forma de vídeo com as respostas dos questionamentos propostos nesta intervenção.

\section{Análise da atividade desenvolvida}

A seguir, são descritos os resultados emergentes da intervenção pedagógica realizada, incluindo algumas das construções realizadas no aplicativo e as respostas apresentadas pelos estudantes, quanto aos conceitos matemáticos subjacentes à atividade. Para preservar a identidade dos sujeitos, os mesmos estão representados por E1T1, E2T2, e assim sucessivamente. Optou-se por E para estudante e T para diferenciar a turma a qual pertencia.

$\mathrm{Na}$ atividade que envolvia a construção de retas paralelas e análise dos coeficientes, pode-se observar a facilidade por parte dos estudantes, em perceber que a questão de paralelismo acontece quando as retas possuem $o$ mesmo coeficiente angular. Também foi possível observar que os grupos perceberam o termo independente como o local que a função intercepta o eixo y. A Figura 3 apresenta uma das construções elaboradas pelos estudantes.

Figura 3: Construção no APP GeoGebra de uma das atividades

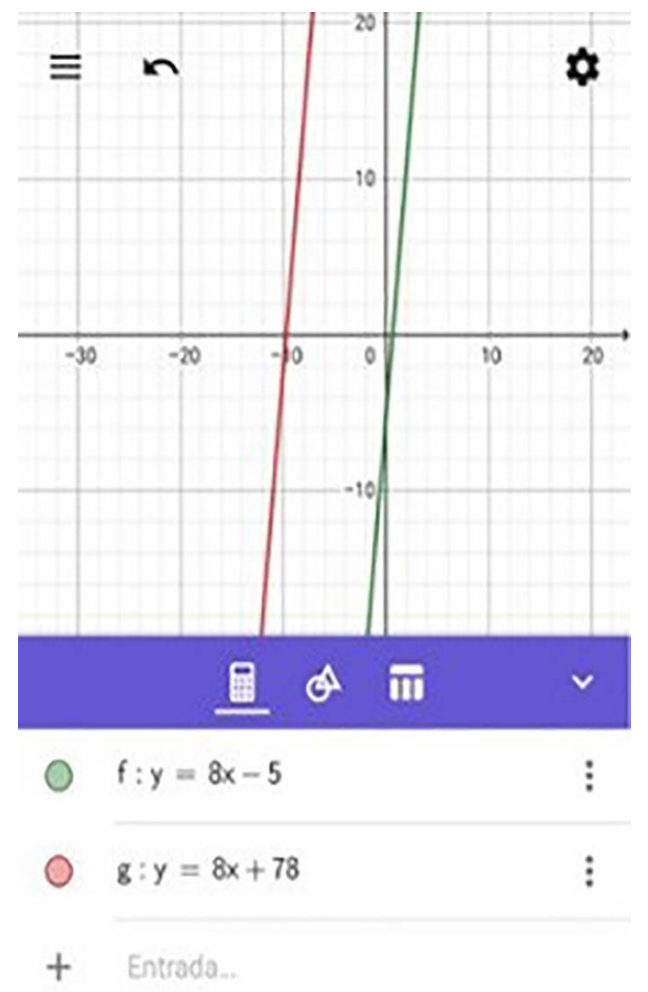


Foi possível perceber que os estudantes compreenderam que para duas retas serem paralelas precisam ter o mesmo coeficiente angular. Fator este importante para a compreensão de outros elementos nas funções, como a influência do coeficiente linear e dos sinais. Já na atividade que envolvia retas perpendiculares observou-se que os estudantes conseguiram responder às questões relativas ao perpendicularismo. A Figura 4 apresenta a construção realizada pelos estudantes E25T1 e E32T1.

Os estudantes supracitados destacaram: "As retas cruzaram-se ao cortar o eixo y. As retas se cruzaram porque possuem o mesmo termo independente e coeficiente angular oposto inverso. A reta 1 intercepta o eixo $x$ no $-0,5$ e o eixo y no 1 . A reta 2 intercepta o eixo $x$ no 2 e o eixo y no 1 . Podemos concluir que quando temos duas funções com o mesmo termo independente e coeficientes angulares opostos inversos, as duas retas são perpendiculares."

Figura 4: Construção realizada por dois estudantes

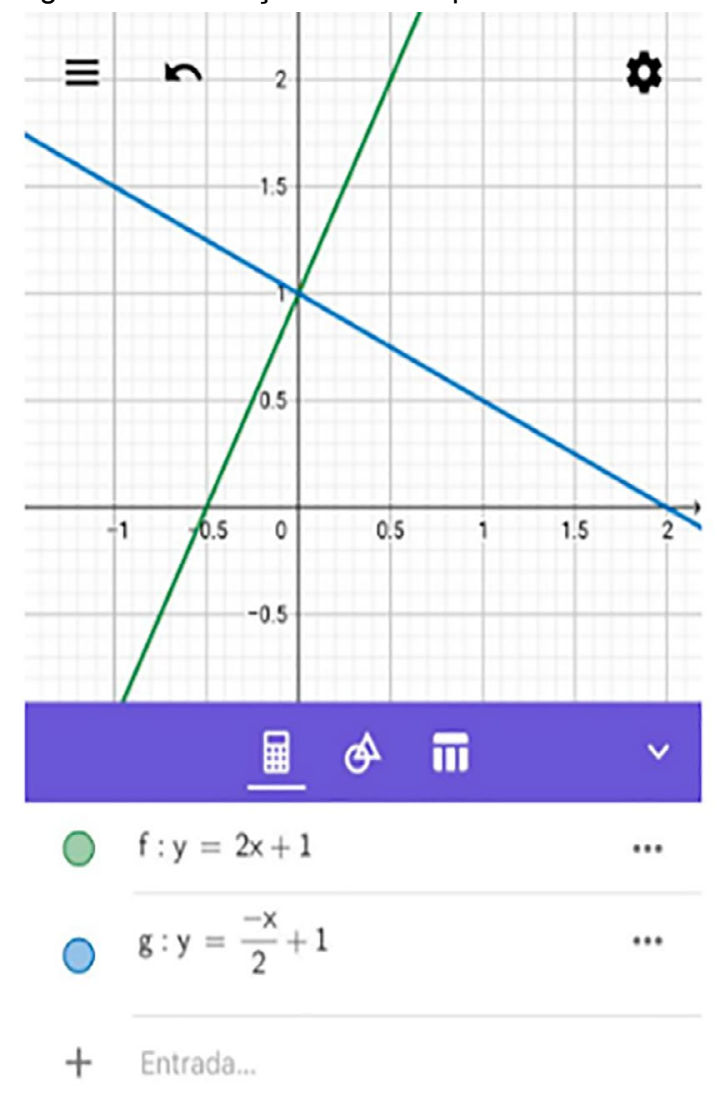


Outro grupo de estudantes, E6T2 e E14T2 destacaram em sua construção (apresentada na Figura 5) que "Podemos observar no gráfico que devido ao coeficiente angular ser diferente as retas se cruzam e o termo independente mostra no gráfico onde as retas interceptam-se no eixo $y$. As retas se cruzam porque um coeficiente angular é positivo e o outro é negativo, fazendo com que as retas se cruzem em determinado ponto. A reta azul intercepta o eixo $x$ no ponto -0,75 e o y no ponto -3. A reta verde intercepta o eixo $x$ no ponto 1,5 e o y no ponto -3. Podemos concluir que caso o termo independente for igual as retas irão se interceptar neste ponto em comum”.

Figura 5: Construção realizada por dois estudantes

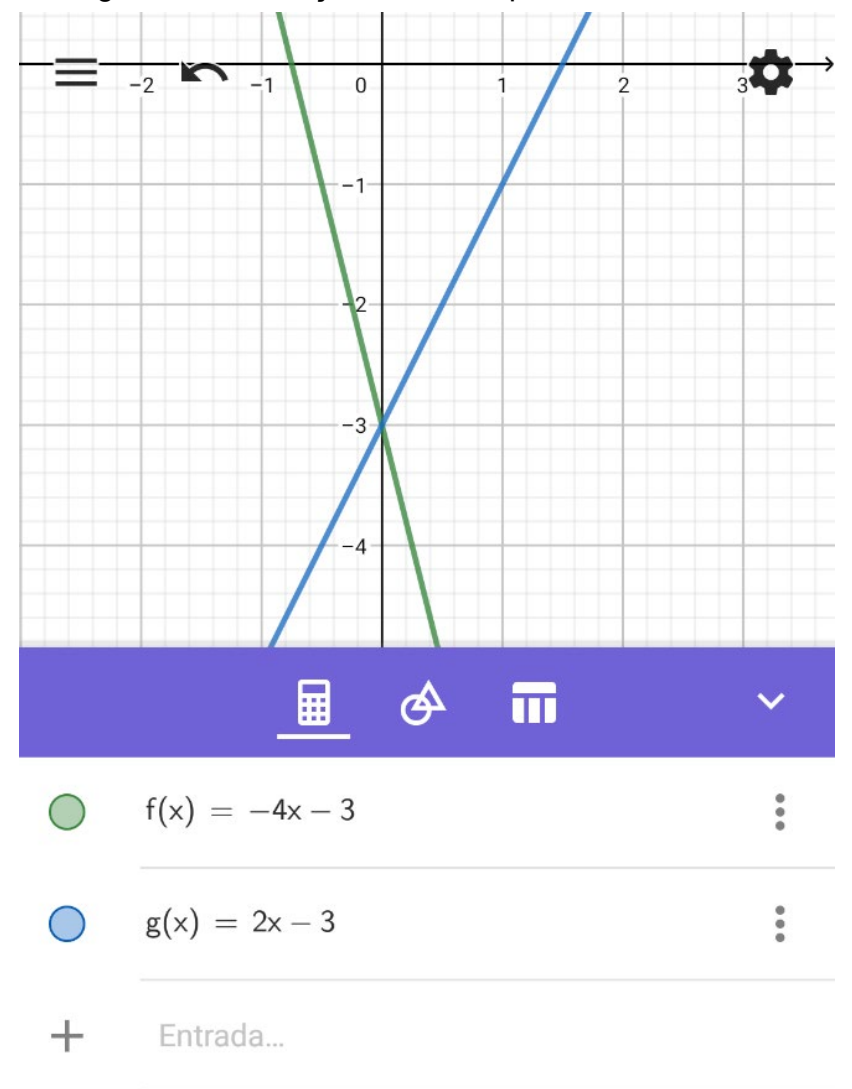


Na segunda atividade proposta aos estudantes, que envolvia a construção de parábolas, com concavidade voltada para cima, os estudantes E2T2 e E17T2 salientaram que: "Observa-se que o gráfico é uma parábola. Com relação a intersecção do eixo x encontra-se dois pontos, significando que o delta da Bháskara é positivo". A Figura 6 apresenta a parábola construída pelos estudantes supracitados.

Figura 6: Construção da parábola por dois estudantes

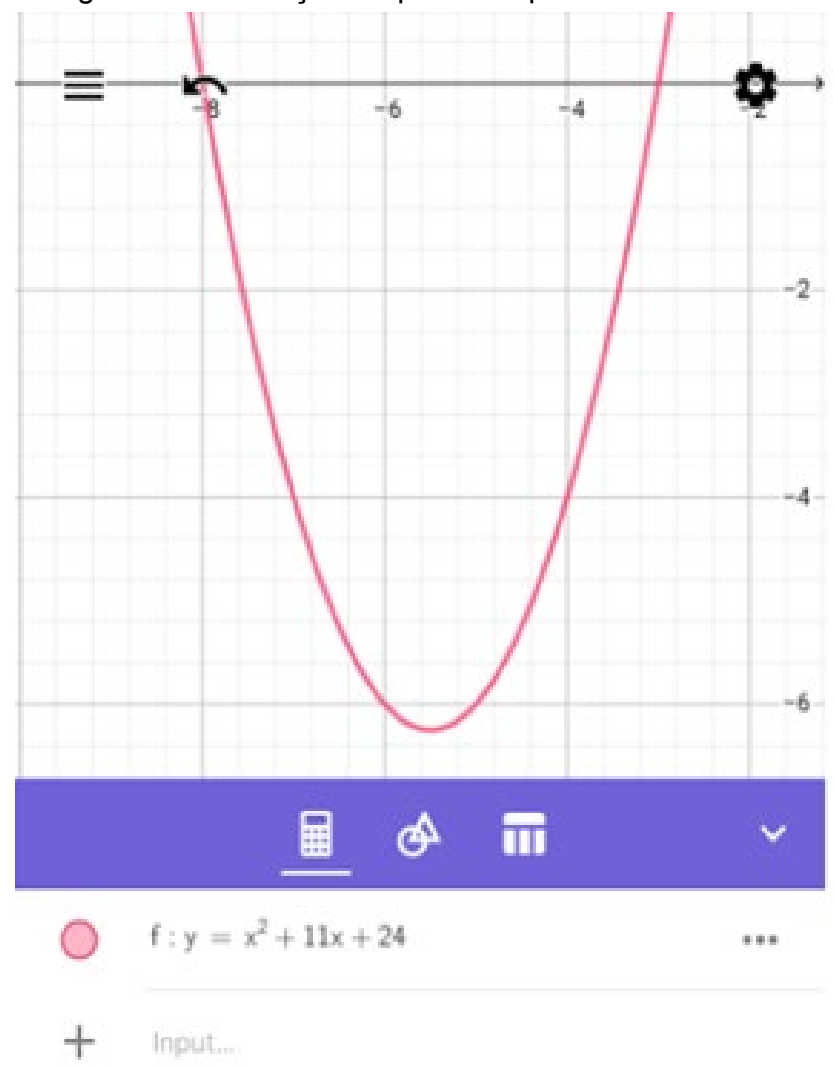


Ao solicitar a construção de uma parábola voltada para baixo, os estudantes E12T2 e E23T2 destacaram que "O gráfico ficou completamente abaixo do eixo $x$, com concavidade voltada para baixo, pois o coeficiente a é negativo. Não houve intersecção com o eixo x porque o delta é negativo”. A Figura 7 expressa essa construção.

Figura 7: Construção da parábola com concavidade para baixo

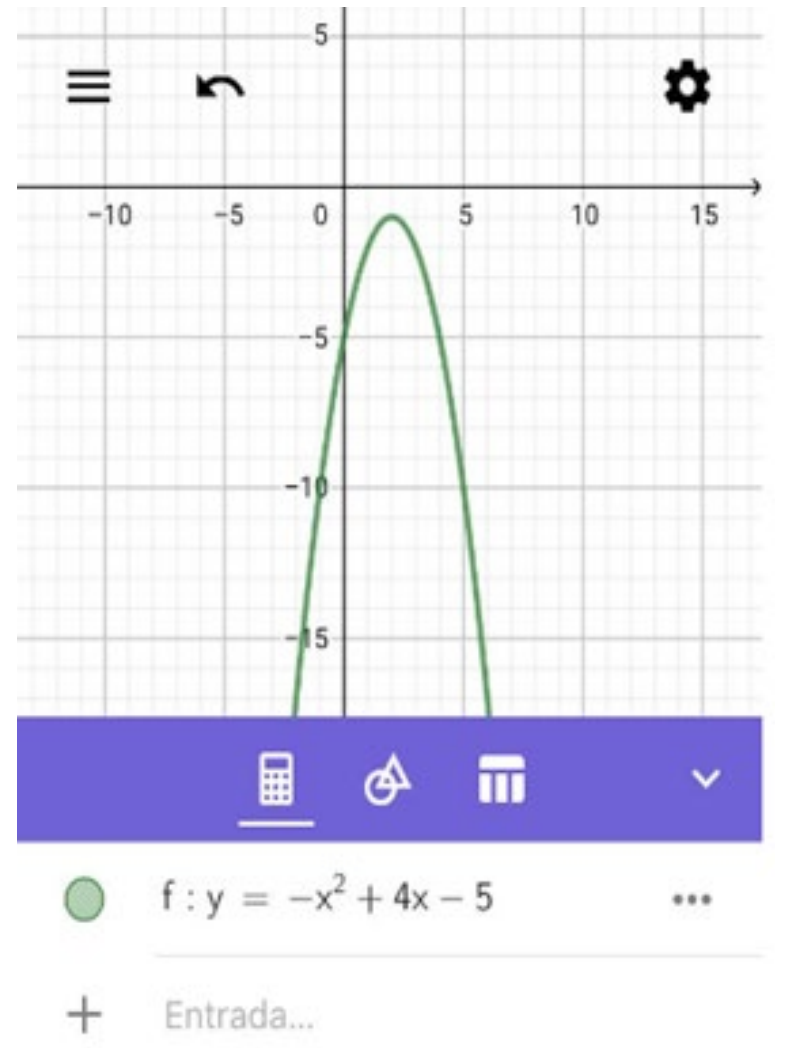

Na última atividade proposta nesta intervenção, solicitou-se que os estudantes realizassem a observação do comportamento de uma função ao alterar os parâmetros. Para isto foi utilizado o recurso do "controle deslizante" disponível no APP. O envio desta atividade para as professoras aconteceu por meio da captura em vídeo do que aparecia na tela do celular.

A primeira tarefa consistiu em utilizar o controle deslizante observado funções de $1^{\circ}$ grau. O grupo dos estudantes E16T1 e E28T1 destacou “Quando o coeficiente 
angular é alterado, altera-se a inclinação da reta e se a mesma é crescente ou decrescente, enquanto ao alterar o coeficiente linear, mudamos a posição da reta em relação ao eixo y. Em ambos os casos ocorre a alteração da raiz da função”.

A Figura 8a e 8b apresenta a função criada por dois estudantes, destacando a mudança na concavidade da parábola, bem como o termo independente e os demais parâmetros da função.

Figura 8a e 8b: Controle deslizante realizado por um dos grupos

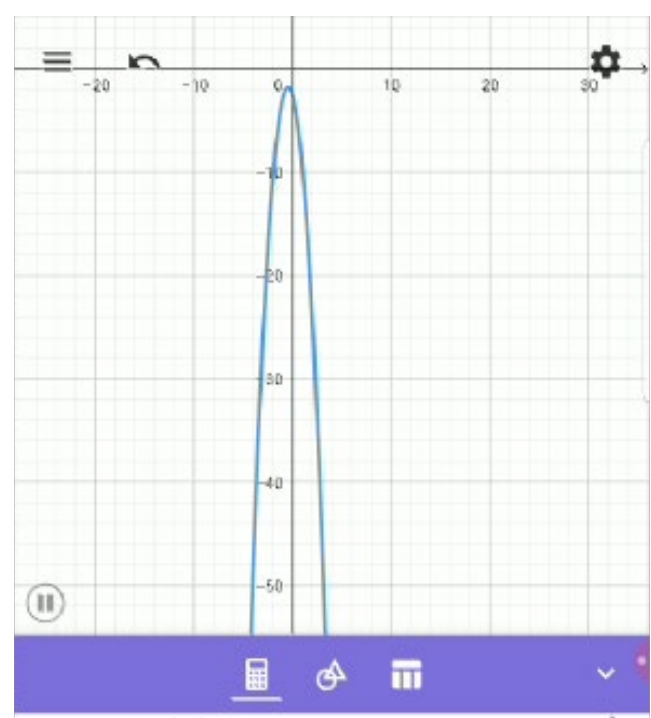

$\mathrm{a}=-3.73$

0

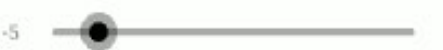

$b=-3.3$

0

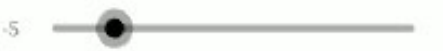

$c=-2.57$

0

$-5$

$f: y=a \cdot x^{2}+b \cdot x+c$

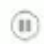

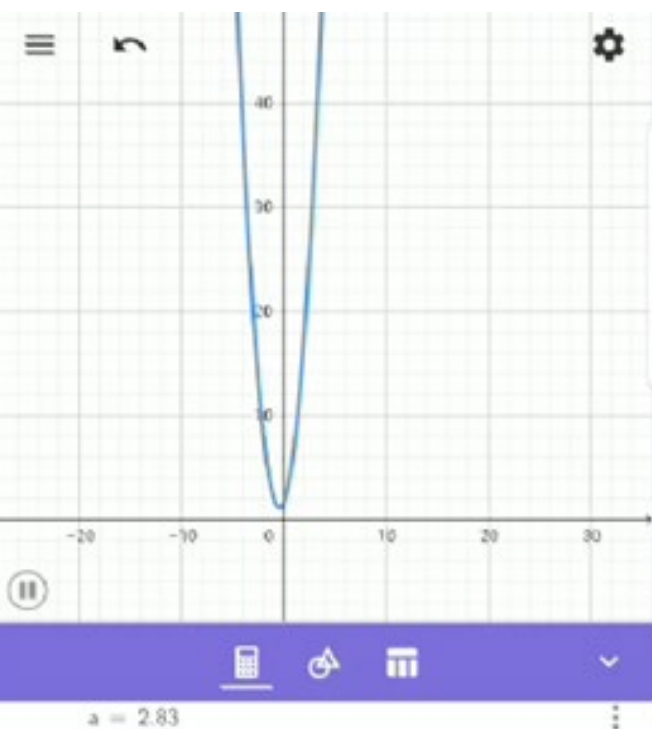

0

0

$b=2.4$

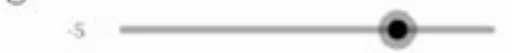

$c=167$

0

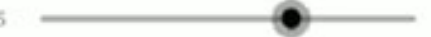

( $f: y=a \cdot x^{2}+b \cdot x+c$

A seguir, são apresentadas as explicações descritas pelos estudantes E4T1 e E8T1 referente à atividade do controle deslizante. 
"Ao alterar os valores do coeficiente a, a parábola se torna positiva ou negativa. Quando alteramos o coeficiente b muda as raízes e o vértice. E quando alteramos o coeficiente c muda o termo independente."

Pelas transcrições apresentadas pelos estudantes percebe-se a modificação de subsunçores ${ }^{2}$ ao incorporarem na escrita, elementos essenciais dos conteúdos trabalhados, o que não era perceptível antes da realização da atividade. Conforme a teoria da aprendizagem significativa de David Ausubel (1982) novas ideias e informações podem ser aprendidas e retidas na medida em que conceitos relevantes e inclusivos estejam disponíveis na estrutura cognitiva do indivíduo, comportando-se como âncora para novas ideias e conceitos.

Em sua teoria Ausubel (2003, p. 3) destaca que "a aprendizagem significativa envolve uma interação seletiva entre o novo material de aprendizagem e as ideias preexistentes na estrutura cognitiva", ocorrendo uma ancoragem, onde as ideias preexistentes são ligadas às novas ao longo do tempo. Ou seja, o indivíduo compreende conceitos e estabelece relações entre estes sinônimos.

Na teoria de Ausubel (1982) uma das condições importantes para ocorrência de aprendizagem significativa é que o material a ser utilizado (livros didáticos, softwares, atividades experimentais, simulações computacionais, entre outros) seja potencialmente significativo. Conforme Ausubel (2003, p. 62):

A estrutura cognitiva existente - a organização, estabilidade e clareza de conhecimentos de um indivíduo numa determinada área de matérias, em determinada altura - considera-se o principal fator a influenciar a aprendizagem e a retenção de novos materiais de instrução potencialmente significativos na mesma área de conhecimentos.

Portanto, o uso de tecnologias durante as aulas pode contribuir na predisposição dos estudantes a trabalhar de modo ativo, na busca de soluções para os problemas que lhes são propostos. Outro fator importante na teoria da aprendizagem significativa diz respeito à predisposição para a aprendizagem. Esta tem um papel importante na aquisição de novos conceitos, uma vez que o aprendiz precisa estar motivado e interessado. O processo de aprendizagem e o produto dependem da predisposição do indivíduo.

Resumidamente, conforme Ausubel (2003), para que ocorra a assimilação três aspectos importantes são necessários: aquilo que o aluno já sabe; os materiais educativos devem ser potencialmente significativos - ter significado lógico; o aprendiz deve ter subsunçores especificamente relevantes. 


\section{Considerações finais}

As tecnologias, em especial os softwares e aplicativos, em um ambiente com tecnologias digitais, proporcionam uma maior interação entre os participantes, constituindo um fator positivo ao aprendizado, tendo em vista a construção de novos conceitos. O APP GeoGebra Graphing Calc possibilita condições para que os estudantes possam reconhecer a representação gráfica de funções polinomiais de $1^{\circ}$ e $2^{o}$ graus, bem como expressar a relação entre os coeficientes das funções com sua representação gráfica e algébrica.

Ao término da proposta de intervenção pode-se inferir que o APP GeoGebra Graphing Calc é de fácil manuseio, facilita e dinamiza o processo de aprendizagem, sendo que o seu uso teve boa aceitação pela maioria dos alunos. Além disso, ele proporcionou a interação entre os estudantes e também com o próprio aplicativo, permitindo aos mesmos chegarem às suas próprias conclusões. As Tecnologias de Informação e Comunicação são apreciadas pelos estudantes por se aproximarem do seu cotidiano, permitindo interatividade e a construção ativa do conhecimento, configurando mais um recurso para uma prática pedagógica motivadora da aprendizagem.

Portanto, a utilização de tecnologias digitais pode contribuir para a ocorrência da aprendizagem significativa dos estudantes. Para trabalhos futuros, seria interessante a investigação do GeoGebra em outros conteúdos da Matemática, bem como, de outros softwares e aplicativos também em outras áreas do conhecimento, como a Química, Física e Biologia, permitindo que os estudantes, principalmente, na Educação Básica, participem ativamente da construção do seu conhecimento.

Cabe salientar que ao término deste relato de experiência as autoras sentem-se motivadas a explorar outras possibilidades com o GeoGebra, nas diferentes séries que atuam, bem como, outras tecnologias digitais, como os simuladores PhET Interactive Simulation, um projeto da Universidade do Colorado (EUA) ${ }^{3}$, que surgiu como uma proposta para melhorar a maneira como a ciência é ensinada e aprendida, relacionando áreas da ciência da natureza com explorações matemáticas. 


\section{APP GeoGebra Graphing Calc: articulations of Mathematics and technologies in Basic Education}

\section{Abstract}

Mathematics teaching, in many contexts, is still detached from technologies. Technological resources, in general, have not been used in teaching and learning processes in different subjects, an aspect reinforced by the lack of teachers' technological training and the predominant school culture, in which there is an emphasis on the expository approach of knowledge. The focus, most of the times, has been on the transmission of scientific knowledge, since the teaching of this discipline often occurs through the presentation of concepts, rules and formulas, inarticulately, with no meaning and distant from technologies, constituting in an obstacle to learning. The use of technologies has often been pointed out in academic discussions as a relevant didactic resource. Digital technologies can play a key role in promoting meaningful learning in mathematics because they help students learn by establishing interrelationships between theoretical and practical knowledge inherent in school knowledge processes. In this context, this paper presents a report of experience developed in the first year of high school in a private school in Erechim, RS. The aim of this work is to develop and investigate intervention actions to problematize and improve the teaching of mathematics, enabling the exploration the functions of $1^{\text {st }}$ and $2^{\text {nd }}$ degree with technological resources. For this work we used the APP GeoGebra Graphing, which allows its use in the students' own smartphones. It is hoped that this work can contribute to other teachers to incorporate the technologies in their pedagogical practice.

Keywords: Digital Technologies; APP GeoGebra; High school; Meaningful learning; Mathematics.

\section{Notas}

1 Os responsáveis pelos estudantes assinaram um termo de consentimento de uso das imagens durante as atividades desenvolvidas.

2 A palavra "subsunçor" não existe em português; trata-se de uma tentativa de aportuguesar a palavra inglesa "subsumer". Seria mais ou menos equivalente a inseridor, facilitador ou subordinador.

3 Disponível em https://phet.colorado.edu/pt_BR/

\section{Referências}

ARAUJO, Wellington Alves de. O GeoGebra: uma experimentação na abordagem da função afim. 2014. 130 f. Dissertação (Mestrado) - Fundação Universidade Federal de Sergipe, Aracaju, 2014.

AUSUBEL, David. P. A Aprendizagem significativa: a teoria de David Ausubel. São Paulo: Moraes, 1982.

AUSUBEL, David P. Aquisição e Retenção de Conhecimentos: Uma Perspectiva Cognitiva. Paralelo Editora, LDA. LISBOA. 1. Edição, 2003. 
BORBA, M. C. Coletivos seres humanos com mídias e a produção de matemática. I Simpósio Brasileiro de Psicologia da Educação Matemática, 2002.

BORBA, M. C.; SILVA, R. S.; GADANIDIS G. Fases das tecnologias digitais em Educação Matemática: sala de aula e internet em movimento. Belo Horizonte, 2018.

BORBA, M. C. Coletivos seres humanos com mídias e a produção de matemática. I Simpósio Brasileiro de Psicologia da Educação Matemática, 2002.

Encontro Nacional de Educação Matemática (13.: Cuiabá, 2019). In: Anais do XIII Encontro Nacional de Educação Matemática: Educação Matemática com as Escolas da Educação Básica - Interfaces entre pesquisas e salas de aula. Sociedade Brasileira de Educação Matemática. - Cuiabá, MT, 2019.

FIORENTINI; LORENZATO, S. Investigação em educação matemática: percursos teóricos e metodológicos. Campinas, SP: Autores Associados, 2006.

SOUZA, Francisco Ademir Lopes de. O uso do software GeoGebra como ferramenta pedagógica no estudo de funções quadráticas em turmas de 9 ano do ensino fundamental do CMF. 2012. 106 f. Dissertação (Mestrado) - Centro de Ciências, Universidade Federal do Ceará, Fortaleza, 2012.

SUCKER, Simone Krause. A motivação para aprender do nativo digital pela perspectiva de professores, alunos e da neurociência. 2016. 120 f. Dissertação (Mestrado) - Pontifícia Universidade Católica do Rio Grande do Sul, Porto Alegre, 2016.

TEIXEIRA, Alexandre de Mattos. Aprendizagem significativa de funções através do GeoGebra e de tipos digitais? 2013, 108 f. Dissertação (Mestrado) - Centro Federal de Educação Tecnológica Celso Suckow da Fonseca, Rio de Janeiro, 2013.

VASCONCELLOS, Celso dos Santos. Construção do conhecimento em sala de aula. São Paulo: Libertad, 2005. 